\title{
O ensino de história nas séries iniciais: cruzando as fronteiras entre a História e Pedagogia
}

Sandra Regina Ferreira de Oliveira ${ }^{1}$

\section{RESUMO}

Este artigo propõe uma reflexão sobre as dificuldades que professores e historiadores encontram em transportar os avanços historiográficos para 0 contexto escolar e materiais didáticos. Paralelamente, propõe suceder discussões a respeito do lugar do ensino de História nas séries iniciais do ensino fundamental. Quais as representações que os professores generalistas têm a respeito da história, do passado, do ensino de História? Como os professores articulam o conhecimento espontâneo dos alunos sobre o passado, fruto das relações sociais estabelecidas com seu meio social, com a História ensinada na escola? Os resultados aqui apresentados são parciais e foram elaborados a partir de entrevistas com professores de terceira série e da análise dos guias de livros didáticos da área.

Palavras-chave: história, ensino, aprendizagem, tempo, passado, livro didático.

As reflexões apresentadas neste artigo integram minha pesquisa de doutorado ${ }^{2}$ em desenvolvimento, portanto, os resultados são parciais. 0 estudo busca identificar as dificuldades que, professores e historiadores, encontram em transformar em assunto escolar e em material didático, uma história contada a partir de diferentes temporalidades. Paralelamente, procura-se também suceder discussões a respeito do lugar do ensino de História nas séries iniciais do ensino fundamental. Qual a compreensão que um aluno de sete, oito anos pode formular a respeito da História, do passado? Como ele articula o conhecimento

1 Doutoranda em Educação pela UNICAMP. Professora de Teoria e Prática nas Séries Iniciais do Ensino Fundamental do curso de Pedagogia da UNIOESTE, Universidade Estadual do Oeste do Paraná, Campus Cascavel. E-mail: sandraoliveira@unioeste.br

2 Projeto de doutorado desenvolvido no Programa da Faculdade de Educação da UNICAMP, sob a orientação da Prof. Dra. Ernesta Zamboni. 
espontâneo sobre o passado e, consequientemente sobre a história, fruto das relações sociais estabelecidas até então com seu meio social, com a História (disciplina) ensinada na escola?

Para responder a estas e outras questões escốlheu-se três caminhos: primeiro, as representações dos professores, para compreender como estes entendem o ensino de História para as séries iniciais do ensino fundamental; segundo, os recentes resultados de pesquisas que procuram entender como 0 aluno destas séries, elabora a concepção de tempo; e, terceiro, como os livros didáticos, editados após a elaboração dos Parâmetros Curriculares Nacionais, apresentam a questão das diferentes temporalidades.

Priorizou-se apresentar os resultados parciais referentes às representações dos professores e parte das reflexões sobre os livros didáticos colocados a disposição no mercado editorial. Apesar de configurarem como apontamentos, as informações aqui apresentadas são extremamente interessantes e convidativas a indagações.

\section{O lugar da disciplina História nas séries iniciais do ensino fundamental}

Na última década consolidou-se a divisão dos Estudos Sociais, até então englobando áreas de História e Geografia, em áreas específicas. Não há espaço nesta abordagem para discutir as reais transformações ocorridas a partir desta divisão, defendida por historiadores e geógrafos. Indagações não foram respondidas: como foi (se foi) incorporada pelo professor generalista (que trabalha com todas as áreas do conhecimento) no cotidiano escolar, a mudança de Estudos Sociais em História e Geografia? Essa mudança ocorreu efetivamente na prática pedagógica? 0 que modificou (se modificou) para os alunos? A dificuldade em se trabalhar com Estudos Sociais está sendo superada com a divisão proposta? 0 professor generalista compreende as áreas em suas especificidades? Como será realizada a tão propagada articulação entre os conteúdos? Neste contexto, aos pesquisadores da área de ensino cabe desenvolver pesquisas que possam responder a estas novas indagações.

Fato consolidado é que a divisão instituiu-se. No PNLD/98 - Programa Nacional do Livro Didático, o Guia de Livros Didáticos: $1^{\mathrm{a}}$ a $4^{a}$ série, ainda apresentou a área de Estudos Sociais. No entanto, no texto introdutório da 
área, os objetivos foram apresentados separadamente, em parágrafos específicos: Geografia: "compreensão dos processos responsáveis pela conformação e pela ordenação do espaço físico brasileiro e mundial, mediante a identificação das relações que, sob a influência desses mesmos processos, se estabelecem entre a sociedade e a natureza" (1998, p.337) e, História:

formação do cidadão, como indivíduo situado historicamente, consciente da sua dimensão social, no seu tempo, e capaz de entender e analisar a dinâmica das organizações sociais, cuja influência se exerce - em diferentes locais e momentos - sobre os mais variados aspectos da vida cotidiana, e também sobre os diferentes processos históricos. Esse objetivo se concretiza mediante a aquisição de um conjunto de conhecimentos, fundados em conceitos como os de tempo, espaço, cultura, sociedade, relações sociais, poder, trabalho e natureza (1998, p. 337).

Na seqüência são interligados:

esses conceitos não podem ser estudados isoladamente. Devem ser vistos, na escola, como partes de uma textura unificada. Por exemplo: o estudo do meio em que vive 0 aluno, e das suas condições locais, deve contribuir para a formação do conceito de espaço, ligado a aspectos básicos das relações entre indivíduos e entre grupos sociais, e das relações entre estes e o meio ambiente. É impossível estudar o espaço sem a noção de contemporaneidade, que supõe as noç̃̃es de tempo, simultaneidade, passado, presente e futuro, sequiência, calendários etc (1998, p.337), talvez por questões pedagógicas ou, como justificativa para, ainda, persistirem os livros de "Estudos Sociais" quando, há muito, os pesquisadores das áreas apontavam para a necessidade de separação.

Nesta pesquisa, mapeou-se quantos livros de Estudos Sociais e de áreas específicas (História e Geografia) foram incluídos no Guia. Utilizou-se como

\footnotetext{
3 No PNLD/98, us livros das áreas de Língua Portuguesa, Matemática, Ciências e Estudos Sociais avaliados pelo MEC - Ministério da Educação e do Desporto, foram apresentados aos professores em um único volume subdividido em áreas. No PNLD/2004 as áreas foram agrupadas em Língua Portuguesa e Alfabetização, Matemática e Ciências, História e Geografia e, Dicionários. Os quatro volumes do Guia de Livros Didáticos/2004, estão disponíveis na página: <hitp://www.mec.gov.br/sef/fundamental/avaliv.shtm>
} 
critério de classificação, a especificação contida na capa do livro. Ressalta-se que foram excluídas, sessenta e três obras sendo: vinte e duas destinadas à $4^{\mathrm{a}}$ série, dezoito à $3^{\mathrm{a}}$ série, doze à $2^{\mathrm{a}}$ série e onze à $1^{\mathrm{a}}$ série. Estes livros não foram considerados na análise.

A tabela 1 apresenta o resultado da classificação. Apesar da predominância de Estudos Sociais, é significativa a oferta de livros didáticos para a área específica de História. Com qual livro o professor escolheu trabalhar? Por quê? Essas respostas podem auxiliar na compreensão de como a divisão foi recebida no contexto escolar e fornecer dados para as questões apresentadas acima.

Tabela 1 - Classificação dos livros quanto à área de conhecimento. PNLD/98.

\begin{tabular}{|l|c|c|c|c|c|c|}
\hline & Estudos Sociais & $\begin{array}{c}\text { Integração } \\
\text { Social e outros }\end{array}$ & $\begin{array}{c}\text { Históriae } \\
\text { Geografia }\end{array}$ & História & Geografia & Total \\
\hline $1^{2}$ série & 7 & 2 & 2 & 2 & 1 & 14 \\
\hline $2^{2}$ série & 2 & & & 2 & & 4 \\
\hline $3^{a}$ série & 1 & & 1 & 1 & & 3 \\
\hline $4^{n}$ série & 5 & & 1 & 1 & 1 & 8 \\
\hline Total & 15 & 2 & 4 & 6 & 2 & 29 \\
\hline
\end{tabular}

Fonte: Guia de Livros Didáticos, $1^{\mathrm{a}}$ a $4^{\mathrm{a}}$ séries/PNDL/98, p 341-398.

Neste artigo, esses dados são apresentados para serem analisados em contraposição aos referentes ao PNLD/2004, tabela 2, visto que, neste último, aponta-se que "os alunos do Ensino Fundamental, a partir do PNLD 2004, não terão mais em seu currículo a disciplina Estudos Sociais. (...) Com esta medida, consagra-se o desejo que vinha sendo expresso há vários anos pelos especialistas das duas áreas, para que se resguardassem as especificidades de

4 Foram classificados em "Integração social e outros" um livro de la série, que traz especificado como sendo de "Integração Social" e outro que não apresenta informação a respeito. 
seus respectivos corpos conceituais também no ensino e na elaboração dos livros didáticos" $(2003,33)$. Portanto, os livros inscritos no programa em 2004 classificam-se, finalmente, em áreas específicas.

Tabela 2-Distribuição dos livros de História e Geografia avaliados no PNLD/2004.

\begin{tabular}{|l|c|c|c|c|}
\hline & História & Geografia & \multicolumn{2}{|c|}{ Livro regional } \\
\hline & & & História & Geografia \\
\hline $\begin{array}{l}\text { Coleções } \\
\text { recomendadas }\end{array}$ & 16 & 20 & 14 & 9 \\
\hline Coleções excluídas & 09 & 05 & 10 & 8 \\
\hline Total & 25 & 25 & 24 & 17 \\
\hline
\end{tabular}

Fonte: Guia de Livros Didáticos, $1^{\text {a a }} 4^{a}$ séries/PNLD/2004, V. 3, Páginas 36, 167 e 169.

Consolida-se o desejo dos especialistas das áreas. Convém explicar, que a separação das disciplinas de História e Geografia nas séries iniciais do ensino fundamental só pode contribuir para a melhoria da qualidade de ensino e partilha-se neste estudo de tal posicionamento dos especialistas das áreas. No entanto, almeja-se nesta pesquisa verificar em que estas mudanças contribuíram na aprendizagem de História.

Na última década, a pesquisa no ensino de História de $5^{a}$ a $8^{a}$ séries avançou consideravelmente ${ }^{5}$. Paralelamente, apesar da mudança $a^{6}$ na área de Estudos Sociais percebe-se que não se construiu uma nova prática pedagógica nas séries iniciais relacionada à área.

Nas séries iniciais a situação do ensino de História é bastante diferente. Há particularidades que necessitam serem apontadas para melhor entendimento dos problemas. Primeiro no campo da pesquisa no ensino de História: poucos historiadores interessam-se pelo processo de construção do conhecimento

5 Sobre esses avanços pesquisar, principalmente em SCHMIDT e CAINELLI (1999). Nesta obra são apresentados artigos que resumem as recentes pesquisas na área. Ressaltam-se os trabalhos de: ABUD (p. 149-156); ARAÚJO (p. 237-251); GASPARELLO (p. 276-285); MUNAKATA (p. 224-231); SOUZA (p. 301-313) E ZAMBONI (p. 422-433).

6 Quanto ao assunto, procurar ABUD (1999); SIMAN (2003); OLIVEIRA (2003); BARCA (2000); CARRETER0 e LIMON (1997); DUT'RA (2000) e ARAÚJO (1998). 
histórico em crianças. Muitos sequer acreditam na possibilidade da criança aprender História nas séries iniciais ${ }^{7}$.

A pesquisa sobre 0 assunto transita por três áreas distintas: História, Pedagogia e a Psicologia. Os loucos que se aventuram são desprezados enquanto pesquisadores, principalmente, por historiadores e pedagogos. Quando historiadores são questionados em sua competência pelos pedagogos (visto que as licenciaturas em História não habilitam para o magistério nas séries iniciais do ensino fundamental). Caso sejam pedagogos, as pedras são lançadas por historiadores (visto que a graduação em Pedagogia não aborda questões consideradas fundamentais para os historiadores).

Como o objeto de sua pesquisa impõe o diálogo com ambos, esse pesquisador vive com um pé em cada canoa equilibrando-se como pode para não ser abandonado aos tubarões (talvez o desejo dos pesquisadoreshistoriadores-puros e dos pesquisadores-pedagogos-puros, visto que esse ser híbrido incomoda a ambos sempre lembrando que não há saberes pedagógicos sem conteúdos específicos e, não há conteúdos específicos que possam ser transmitidos sem os saberes pedagógicos).

A segunda particularidade loca-se no campo de formação de professores (aqui entendidos como pedagogos e historiadores). Nos currículos de ambos os cursos há lacunas, principalmente, quanto às metas do ensino de História para as séries iniciais. Mesmo quando as disciplinas denominadas pedagógicas são ministradas nos cursos de Pedagogia ou as disciplinas de Metodologia do Ensino de História são ministradas por historiadores, verifica-se total desarticulação. Os docentes do curso de História não estão preocupados com a formação do pedagogo e, vice-versa.

A terceira e última particularidade trata da não transposição para os livros didáticos das discussões recentes relacionadas à historiografia e ao ensino de História. Uma análise criteriosa nas resenhas publicadas no Guia de Livros Didáticos/2004, área de História, referente às coleções que foram indicadas com ressalvas ${ }^{8}$ indica vários problemas quanto à abordagem historiográfica.

Retirou-se do documento algumas considerações que apontam os problemas encontrados quanto a transposição didática, como:

7 Sobre o assunto ver BARCA (2000) e CARRETERO (1997).

8 As coleções no PNLD - 2004 foram classificadas em: recomendada com distinção, recomendada e recomendada com ressalva. 
o encadeamento entre diferentes realidades espaço-temporais é superficial, encontrando-se simplificações explicativas, e nota-se ausência de explicitação da diversidade e do conflito (p. 74); a historicidade das experiências sociais é pouco explorada e não se registra uma abordagem problematizadora da relação presentepassado(p. 78); as matrizes teóricas das propostas metodológicas relativas ao conhecimento histórico não são explicitadas. Há múltiplas simplificações explicativas, indicando defasagem em relação à produção historiográfica recente (p. 90); há um número reduzido de temas historiográficos, tratados, em geral, de forma simplificada e desatualizada(p. 94); além disso, os conceitos e categorias próprias do conhecimento histórico não são construídos de forma adequada(p. 110); a construção do conhecimento histórico não é trabalhada a partir de problematizações e de fontes (p. 114).

Analisar essas particularidades, conforme exposto acima, permite entender as possibilidades e limitações da aprendizagem em História nas séries iniciais. No entanto, pesquisadores do ensino não podem fazer isto sem parceria com os professores das séries iniciais não entendidos como campo de pesquisa mas, como construtores de saberes, como parceiros na empreitada de entender os problemas e construir possíveis alternativas, contribuindo com historiadores e pedagogos no processo de repensar o ensino de História.

Foi com este intuito que os professores foram chamados a participarem desta pesquisa. Convidados a refletirem sobre sua práxis, os professores deixam de ser considerados como simples elos de transmissão de conteúdos elaborado em determinadas épocas e, selecionados, por diversas razões, como currículo básico a ser transmitido aos alunos. 0 diálogo teórico-prático é condição primeira para que possa haver uma reflexão sobre a práxis. Dialogar não supõe hierarquizar. A teoria, utilizando as palavras de PIMENTA, "projeto de uma prática inexistente, determina a prática real e efetiva. Por outro lado, a teoria que ainda não está em relação com a prática, porque se adianta a ela, poderá ter essa relação posteriormente - nova teoria de nova prática e assim por diante" (1997, p. 92) 


\section{As representações do professores sobre 0 ensino de História nas séries iniciais}

Participaram da primeira fase da pesquisa, dezessete professores ${ }^{9}$ de terceira série do ensino fundamental. Contribuíram, significativamente, fornecendo informações para que fosse possível identificar quais as concepções que formulam sobre a História; como elaboram seus planejamentos; como utilizam o livro didático; como articulam conteúdos desta disciplina com as demais; como trabalham com a temporalidade na história; e, qual a relação que estabelecem entre o que aprenderam nos cursos de formação (ou aprendem nos de qualificação que fazem constantemente) com as atividades desenvolvidas em sala de aula.

A escolha por professores de terceira série do ensino fundamental justificase porque é nesta série que conteúdos característicos da ciência histórica começam a ser trabalhados ${ }^{10}$. As representações que os professores formulam do lugar da História na $1^{\mathrm{a}}$ e $2^{\mathrm{a}}$ séries merecem destaques. Duas falas são significativas ${ }^{11}$ :

como já trabalhei com primeira e segunda série, ficamos tão ansiosos com a alfabetização, com a Matemática que a gente acha que Estudos Sociais, Geografia, Educação Artística são matérias que não vão fazer diferença (Professora 01).

Na primeira série, o professor está tão empenhado em alfabetizar - eu tenho visto isto assim em todos esses anos - e a gente também quando está na sala de aula, a preocupação é tanta em alfabetizar, a preocupação que ele aluno vai estar escrevendo, estar lendo, estar produzindo alguma coisa é tanta que à parte de História fica assim uma coisa que eu vou trabalhar quando der (2003, entrevistas gravadas).

90 projeto prevê a participação de quarenta professores.

${ }^{10}$ Apesar das possíveis contradições que esta afirmação pode trazer, foi feita a opção de trabalhar na perspectiva de autores como CARRETER0 e LOWENTHAL, que estudam e definem o que podemos considerar como pertencente à área de história ou a outras áreas do conhecimento. Para sustentar tal discussão é necessário responder qual o objeto do ensino de história nas séries iniciais do ensino fundamental. É possível estabelecer uma diferenciação entre estudos sociológicos e estudos históricos? 0 que confere um caráter distinto a esta disciplina nestas séries?

${ }^{11}$ Os nomes dos professores não serão apresentados, conforme solicitação dos mesmos. 
Considerando as informações recebidas, verifica-se a posição secundária que 0 ensino de História continua a ocupar na divisão de tempo e espaço no cotidiano escolar. Toda atenção dos professores está voltada para o processo de aquisição da leitura e da escrita.

Outra contribuição dos professores refere-se ao objetivo do ensino de História na terceira série. Solicitou-se que escrevessem a respeito. Os dezessete professores relacionaram trinta objetivos diferentes. Somente dois objetivos foram repetidos por mais de um professor: sete (23\%) apontam como principal objetivo, mostrar para a criança que ela tem uma história de vida e que é importante na sociedade; três (10\%) indicam que é mostrar que existe uma relação entre os fatos passados com os acontecimentos diários.

Nas outras respostas (67\%) não houve repetição, apesar de semelhanças significativas. É interessante apresentar esses objetivos, tal qual foram apontados pelos professores:

possibilitar aos alunos a percepção das transformações que ocorrem no tempo e no espaç̧; estabelecer as relaçoes entre homem e os elementos natureza; estabelecer relações entre os homens através do trabalho; levar a criança a perceber que a história é um processo constante de mudança; auxiliar na formação do aluno no que tange a vivenciar o presente, passado e futuro, fazendo refletir enquanto cidadão; fazer a criança se socializar com o grupo de convivência na escola; saber localizar-se no tempo e no espaço; conhecer a história de outros grupos de convivência; mostrar o modo de vida dos homens através dos tempos; levar a criança a adquirir conhecimentos da realidade que ela vive e a cerca; aprender sobre a sua identidade pessoal e ir, a longo prazo, adquirindo conhecimento dentro da História da forma mais real possível, mesmo com conhecimentos focados em livros didáticos; aprender a entender a realidade da época em que surgiram os fatos; levar a criança a não viver só no imaginário; levar os alunos a interpretarem os fatos apresentados a elas; cuidar também ao enfocar as datas comemorativas com o real; a função é levar o aluno a conhecer o passado, a fim de situá-lo no presente de forma que ele possa interferir no seu cotidiano; resgatar os seus antepassados; formar cidadãos (direitos e deveres); desenvolver o senso crítico; perceber mudanças e permanências que ocorrem no cotidiano; estabelecer noções de tempo; reconhecer-se como aggente histórico; tomar conhecimento da 
história de sua família, do bairro, do município, do país e até mesmo da terra;trabalhar com os alunos que somos pessoas inseridas em uma realidade social, política e econômica e que estamos em constante transformação; compreender a dinâmica que rege o mundo a sua volta; levar a criança a se localizar no tempo e no espaço; incentivar a socialização; refletir sobre 0 desenvolvimento histórico dos fatos que interferem e contribuem com o seu desenvolvimento intelectual e social.

0 que essas informações revelam? A indefinição nas respostas sobre 0 objetivo do ensino de História nas séries iniciais do ensino fundamental, aparente nos discursos elaborados pelos professores, contrapõe à definição explícita dos objetivos apresentados pelos mesmos professores para o ensino de Português. Todos professores que participaram da pesquisa, apesar de conhecerem diferentes teorias que explicam a questão da aprendizagem da leitura e da escrita, explicitam que o objetivo da disciplina de Língua Portuguesa na escola é ensinar o aluno a ler, interpretar e escrever. Quando apontam que o objetivo do ensino de história é levar a criança a perceber que ela tem uma história e que é importante na sociedade, questiona-se se a escola pode, ou tem o poder de tal empreitada.

Uma das características que confere caráter científico ao conhecimento histórico e, conseqüientemente, ao seu ensino, é a sua natureza coletiva que a separa da memória. Segundo LOWENTHAL,

o passado que eu recordo é parcialmente compartilhado com os outros, boa parte dele é unicamente meu. Mas o conhecimento histórico é, por sua própria natureza, produzido e compartilhado coletivamente; a percepção histórica implica atividades em grupos. (...) Para lembrar e comunicar esse passado é preciso haver instituições complexas e duradouras. Por essa razão "a história deve ser estudada como uma atividade social" (1998, p.109).

Está elaborada a primeira questão a ser analisada para prosseguir com a discussão sobre a História como disciplina nas séries iniciais do ensino fundamental: qual o lugar da memória? Qual o lugar da história? Qual a diferença entre História e memória no cotidiano escolar? 
Ao buscar compreender o lugar que a memória ocupa no ensino de História para crianças, outra categoria se apresenta: o passado. Não é possível discutir a questão do ensino de história sem discutir como cada uma destas categorias - memória e passado - se fazem presentes no que os professores denominam por História e que se transforma, na escola, em matéria prima do saber a ser ensinado.

Memória, passado, história e tempo, categorias essenciais constituintes do ensino de História, são reinterpretados no cotidiano escolar. Este cotidiano é determindo pela cultura da escola e pela cultura escolar. FORQUIN denomina cultura da escola o conjunto das "características de vida próprias, seus ritmos e seus ritos, sua linguagem, seu imaginário, seus modos próprios de regulação e de transgressão, seu regime próprio de produção e de gestão de símbolos." (1993, p. 167). A cultura escolar é definida como "o conjunto dos conteúdos cognitivos e simbólicos que, selecionados, organizados, normalizados, rotinizados, sob o efeito dos imperativos de didatização, constituem habitualmente o objeto de uma transmissão deliberada no contexto das escolas." (1993, p. 167)

Entender as representações dos professores sobre História passa, necessariamente, por entender a cultura da escola inserida no cotidiano escolar e como nela atuam todos os sujeitos envolvidos, constituindo-se a cultura escolar. Neste sentido, conforme TARDIF (2000), não basta ouvir o que 0 professor fala a respeito de sua prática, é necessário também olhar para esta prática e tentar estabelecer as possíveis relações entre o que ele constrói enquanto discurso e o que efetiva na prática. A efetivação na prática está carregada de outros saberes: o saber da experiência, o saber curricular e os saberes pedagógicos. Ao lado das categorias selecionadas nesta pesquisa como principais para se entender o ensino: memória, passado, história, tempo; alia-se outra: 0 cotidiano escolar.

É nesta perspectiva que está pesquisa pretende trabalhar com o tempo histórico. Analisar como as contribuições historiográficas sobre as diferentes temporalidades têm chegado até aos alunos; como os autores dos livros didáticos têm transposto para o saber escolar essas como estas novas compreensões e se estas contribuições estão favorecendo uma nova visão sobre o que é história; passa obrigatoriamente, pela compreensão do cotidiano escolar nas especificidades apontadas acima. 
As indagações apresentadas neste texto serão respondidas no prosseguimento desta pesquisa continuando o diálogo com os professores; fazendo acompanhamento das aulas em uma turma de terceira série de uma escola municipal da cidade de Londrina, para analisar como se expressam no cotidiano escolar as representações sobre a história a ser aprendida para, enfim, tecer considerações sobre o objeto principal desta pesquisa: como as discussões historiográficas sobre o tempo histórico efetivam-se (ou não) na sala de aula.

\section{Bibliografia}

ABUD, K.M. Temporalidade e Didática da História. In: ZAMBONI, E; CERRI, L.F e MARTINS, M. C. (orgs.). Anais do III Encontro Nacional de Pesquisadores do Ensino de História. Campinas: Gráfica da FE/UNICAMP, 1999. p. 31-36.

ARAÚJO, H.M.M. Tempo-Rei - A noção de tempo em adolescentes de 10 a 14 anos: implicações para o ensino de História. Rio de Janeiro: PUC/RJ, 1998. 155 p (Dissertação, Mestrado em Educação).

BARCA, I. O Pensamento Histórico dos Jovens. Braga: Editora Universidade do Minho, 2000.

CARDoSO, S. H. B. Discurso e ensino. Belo Horizonte: Autêntica, 1999.

CARRETERo, M. Construir e Ensinar - As Ciências Sociais e a História. Porto Alegre: Artes Médicas, 1997.

DUTRA, S.F. As crianças e o desenvolvimento da temporalidade histórica. Belo Horizonte: Faculdade de Educação da UFMG, 2003. 245 p.

. 0 ensino de História para crianças. Revista Presença Pedagóoica, v. 6, n. 31, jan/fev/2000, p.61-69.

FORQUIN, J. C. Escola e cultura: as bases sociais e epistemológicas do conhecimento escolar. Porto Alegre: Artes Médicas, 1993.

GAUTHIER, C. Por uma teoria da pedagogia: pesquisas contemporâneas sobre o saber docente. Ijuí,RS: Editora UNIJUÍ, 1998.

GILLY, M. As representações sociais no campo da educação. In: JODELET, D. As representações sociais. Rio de Janeiro: EdUERJ, 2001. 
GIROUX, H.A..Os professores como intelectuais: rumo a uma pedagogia crítica da aprendizagem. Porto Alegre: Artes Médicas: 1997.

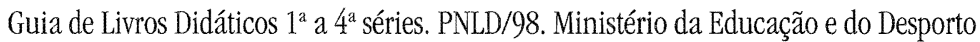
- MEC. Brasília: Imprensa Nacional, 1997.

Guia de Livros Didáticos $5^{\mathrm{a}}$ a $8^{\mathrm{a}}$ séries. PNLD/99. Ministério da Educação e do Desporto - MEC. Brasília: SEF/MEC; FNDE/MEC; CENPEC, 1998.

Guia de Livros Didáticos, Geografia e História. V. 3. Ministério da Educação e do Desporto - MEC. Brasília: MEC, 2003. Disponível em: http://www.mec.gov.br/ sef/fundamental/ avaliv.shtm. Acesso em: 4/04/2003, 11h:11min AM.

JOVCHELOVITCH, S. Vivendo a vida com os outros: intersubjetividade, espaço público e representações sociais. In: GUARESCHI, P.; JOVCHELOVITCH, S. (orgs.) Textos em representações sociais. 6. ed. Petrópolis: Vozes, 2000.

LE GOFF, J. História e Memória. Campinas: Unicamp, 1994

LERNER, D. 0 Ensino e o aprendizado escolar. Argumentos contra uma falsa oposição. In Piaget e Vygotsky. Novas contribuições para o debate. São Paulo; Ática. 1996

LOWENTHAL, D. Como conhecemos o passado. In Projeto História: Revista do Programa de Estudos Pós-Graduados em História e do Departamento de História da Pontifícia Universidade Católica de São Paulo - Trabalhos da Memória. São Paulo, v. 17, 19. 1998.

OLIVEIRA, S.R.F. 0 tempo, a criança e o ensino de História. In: ZAMBONI, E. e ROSSI, V.L.S. Quanto tempo o tempo tem. Campinas: Alínea, 2003. p. 145 - 172.

PIMENTA, S. G. O Estágio na Formação de Professores. Unidade Teoria e Prática? São Paulo: Cortez, 1997.

ROCKWELL, E.; EZPELETA, J. A escola: relato de um processo inacabado de construção. 2. ed., São Paulo: Cortez, 1989.

SALVADOR C.C. Aprendizagem escolar e construção do saber na escola. Porto Alegre: Artes Médicas, 1994.

SCHMIDT, M.A e CAINELLI, M. (org) Anais do III Encontro: Perspectivas do Ensino de História. Curitiba: Aos Quatro Ventos, 1999.

SCHMIDT, M.A. A formação do professor de história e o cotidiano de sala de aula. In: BITTENCOURT; C. (org). O saber histórico na sala de aula. $4^{a}$ ed - São Paulo: Contexto, 2001. 
SILVA, C.S.B.da. Curso de Pedagogia no Brasil: história e identidade. Campinas, SP: Editora Autores Associados, 1999.

SILVA, M. da. Como se ensina e como se aprende a ser professor. Bauru: EDUSC, 2003.

SIMAN, L.M.C. A temporalidade histórica como categoria central do pensamento histórico: desafios para o ensino e a aprendizagem. In: ZAMBONI, E. e ROSSI, V.L.S. Quanto tempo o tempo tem. Campinas: Alínea, 2003. p. 109 - 143.

TARDIF. M. Saberes docentes e formação profissional. Petrópolis: Vozes, 2002.

VEIGA, I.P.A., SOUSA, J.V., RESENDE, L.M.G.de, DAMIS, O.T. Licenciatura em Pedagogia: realidades, incertezas, utopias. Campinas, SP: Papirus, 1997.

ZAMBONI, E. Desenvolvimento das Noções de Espaço e Tempo na Criança in CADERNO CEDES A prática do ensino de história. São Paulo: Cortez, 1984.

Entrevistas.

Professores de terceira série do ensino fundamental: dezessete depoimentos [Março 2003]. Entrevistador: S.R.F. Oliveira. Londrina: Londrina, 2003. 15 fitas cassete (60 min).

\section{ABSTRACT}

This article proposes a reflection about the difficulties that teachers and historians find in transporting the historiographic progresses to the school context and didactic material. Besides, it intends to make discussions regarding the place of History teaching in the initial grades of fundamental teaching. Which representations do the generalist teachers have about history, past, History teaching? How do the teachers articulate the students' spontaneous knowledge on the past, profit of the social relationships established with their social mean, with the History taught at school? The results here presented are partial and they were elaborated from interviews with teachers of third grade and the analysis of the text books guides of the area.

Key-words: history, teaching, learning, time, past, text book. 